\title{
A Portal for a School of Social Work: Going for the Edge
}

\author{
RobertVernon \\ Cynthia Schultz
}

\begin{abstract}
This case study documents how one school of social work addressed the growing complexity of distributing information by developing a state of theart portal and websitesystem to serveits many audiences and campuses. Preliminary findings are discussed.
\end{abstract}

Keywords: Website, design, portal, social work

\begin{abstract}
ocial work education websites often reveal design and functionality problems. Many are nothing more than electronic brochures with little information on programs, faculty lists, and perhaps a smattering of select details (Carlson, 2003). These websites are typically static with very few interactive elements, if any. Some are more dynamic and offer prospective students the ability to apply online or download program information. Many are "placeholders" crafted by non-social work staff who know very little about the profession or the curriculum. Very few are designed to meet the needs of the many different audiences who want information about the profession, the school, or its features (Curl, Bowers \& Bowers, 2003; Vernon \& Lynch, 2003). This case study is for colleagues who want to expand their school's website toward reaching wider audiences, supporting administrative routines, and enhancing the quality of teaching through building a more sophisticated web presence.
\end{abstract}

\section{PROBLEMSAND NEEDS}

Our school hosted a first generation website since 1995 and experienced the typical problems and limitations that developed as information needs and consumer expectations grew:

- Lack of consistency. Visitors were more satisfied when a website had consistent navigation and an attractive overall appearance, yet, navigation and design inconsistencies had cropped up after several updates and revisions. What resulted was a main website that actually looked like several separate websites cobbled together. A visitor could easily think that they were at a different website altogether rather than being in another part of the same one.

Robert Vernon, Ph.D. is Associate Professor, Indiana University School of Social Work, Indianapolis, IN 46202. Cynthia Schultz, MS is Senior Director of Communications, Indiana University Alumni Association, Bloomington, IN 47401.

Copyright $^{\odot} 2003$ Advances in Social Work Vol. 4 No. 2 (Fall 2003) 65-79.

Indiana University School of Social Work. 
- Outdated content. It had been easy to amass considerable information on the website. Once posted, though, a conference announcement or other time-sensitive item tended to become immortal, available long after the event had taken place or the deadline had passed.

- Poor quality content. No one regularly reviewed the website for currency and accuracy. Content sometimes had grammatical and spelling errors that conveyed a lack of scholarship and professionalism.

- Linkrot. Hypertext links that lead nowhere are a common problem with websites. We certainly had our share.

- Overburdened resources. Responsibility for development and maintenance fell on administrative support personnel. Our one in-house technician was already working at capacity. In addition, most administrative support personnel lacked the advanced skills needed to develop and maintain online content. ${ }^{1}$ The process of transferring information was laborious. Text content had to be changed to HTML, introducing errors, and frustrating staff. Long delays became commonplace.

- No uniformity between websites. The Indiana University School of Social Work is completely centralized: We offer four different degrees on five different campuses throughout the state. The Indianapolis campus is the flagship and all policies and programs are centrally managed from this campus. Yet, we had five different websites in place and none of them were similar in any respect. All had independently evolved and there had been no attempt to develop any content or design uniformity.

More subtle problems were emerging, too. As the web was maturing, the user's expectations were maturing as well (Powell \& Gill, 2003). Users expected to find information on the school's website, and they assumed they would get an immediate response - 24 hours a day, seven days per week (Spool, 2001). Our static website with its "one style fits all" design was failing to meet visitors' needs as reflected in numerous informal comments and e-mails. There was a general consensus that the school was rapidly outgrowing its static website and that we also needed to have a system that knit all five campuses together. This problem was taken up by the school's Technology Committee, a faculty, student, and administrative group charged with overseeing technology needs.

The Technology Committee conducted several hearings and interviews with key constituencies and determined the following: All of our university's doctoral applicants had recently been required to submit their applications online, yet, our website could not support this. Prospective BSW and MSW students wanted detailed information and the ability to apply online, as well. Alumni wanted to keep track of each other and know about upcoming events. Faculty wanted enrollment lists and access to student information. Researchers wanted to work collaboratively and share information. Staff wanted access to official calendars and detailed program information. Enrolled students wanted class schedules, syllabi, and graduation requirements. Administrators needed secure access to the financial management systems and budget information. Everyone wanted a new, more interactive, and robust web environment that would support these needs. 
Disability access was paramount. The Technology Committee worried that a cutting-edge solution would limit access to users with special needs. Weneeded a solution that would seamlessly deliver content to all users no matter what type of computing device they used to access the website. Different connection speeds, browsers, and other universal design requirements would have to be taken into consideration as well.

Finally, we were aware that the university's many different computing networks were changing, too, and that any solution we created would have to adjust to them. The Student Information Transaction Environment or "Site"-already quite sophisticated - was being replaced by a new system that promised to integrate everything from enrollments and coursescheduling to tuition and parkingtickets. "Oncourse," Indiana University's course management program that is similar to Web CT and BlackBoard, was becoming universally available and students were starting to demand it. Any solution we selected would need to be compatible with these other initiatives.

\section{GEARING UP}

The chair of the Technology Committee convened a project task force to inventory needs and recommend a solution. The task force consisted of representatives from major constituencies: faculty, students, staff, alumni, and community leaders. This group began to investigate how to transform our static website into a far more adaptable one that would meet current needs and likely adjust to new demands from the university. We decided we needed a central repository for all of the common documents shared by all of the programs on the five campuses within our system. For example, we needed a way to have the identical MSW Student Manual universally accessible. We wanted a way to distribute centrally managed syllabi.

We envisioned a portal-a large, integrated system with a main website for the school and satellite websites for each of the fivecampuses ${ }^{2}$. Each satellite would be stylistically similar yet recognizably distinct so that visitors would visually know that they were still within the same school but on a different campus. An underlying portal structure would provide this visual continuity, assure uniformity when needed, and support the individual needs and characteristics of the different campuses and their programs while making management of the entire school's system far easier. We also envisioned a "distributed system" where authorized staff could immediately post or update information without the bottleneck of converting documents to HTML and waiting for technical support to get them on the server ${ }^{3}$.

One of the first jobs the task force accomplished was to identify and specifically describe the audiences we needed to include. Unlike the current "one size fits all" version, we wanted the new portal to accommodate as many different audiences as possible (Nielsen, 1999; Vernon \& Lynch, 2000). The task force identified six distinct audiences: potential students, current students, alumni, faculty and researchers, administrative and support staff, and external constituencies such as practitioners, agencies, and social service organizations. Each audience had different information needs. 
We then isolated 45 discrete sub-categories within the original six target audiences. The faculty audience, for example, was divided into junior/non-tenured faculty, senior/tenured faculty, visiting faculty, adjunct faculty, teaching practitioners, associate faculty, field instructors, and potential faculty. We used this finegrained listing based on the assumption that different groups within each target audience would have different information needs. Seasoned and tenured faculty, for example, need access to advanced course resources, while associate or adjunct faculty requirefar more basic help. A potential student looking for a Ph.D. program would not be interested in BSW offerings.

The task force then crafted a mission statement along with specific goals and objectives to guide us, based on this initial audience and needs inventory.

"The mission of the Indiana University School of Social Work Web task force is to create an electronic, web based support system that promotes the school in the preparation of knowledgeable professional social workers, through teaching, scholarship, and service, and to support the pursuit of social, political, and economic justice by IUSSW web community members. Through the development of a user friendly, dynamic, and ever-changing school web site, the task force seeks to streamline internal day-to-day school operations, and to build bridges among faculty, staff, students, and the broader practice community in Indiana. Such connections are also intended to support the involvement of IUSSW alumni in continuing social work education and the development of best practices. The IUSSW web site design creates a portal for continued engagement with the broader community, and a gateway into the IUSSW community. In building a web community, the task force seeks to generate electronic resources for users that support the integration of technology into teaching, scholarship, and service. To these ends, the IUSSW web task force seeks to create a web based system that is responsive to the needs of the IUSSW web community."

IUSSW Website Mission Statement Available at: http:// socialwork.iu.edu/site/indexer/ 121/content.htm

Next, thetask force chair made a prototype HTML webpage and shared it and the mission statement with people from the six different audiences. Revisions were made from the resulting feedback, and the task force introduced the refined mission statement and prototype at a full faculty meeting in the spring of 2001 . The faculty were thoroughly dissatisfied with the current website and clearly understood the benefits of this new approach. The faculty unanimously endorsed the portal project and this proved invaluable. It validated the recommendations of the task force and garnered broad-based support. Everyone was coming "on board." Wealso began to realize that a static website, perhaps a little more complex than our current one, would never support our evolving needs. It was becoming clear that we might be overwhelmed by the scope and complexity of this project. We realized that welacked the professional expertise and resources to advance the project successfully.

Fortunately, our dean had a progressive vision for the school that embraced technology. He was very aware of what a good web presence could accomplish and how 
it could advance our many activities. This, combined with complete support from the faculty and staff, set the stage for seeking out the resources we needed.

We needed to expand internal capabilities. We sought out professionals experienced in large-scale web projects. The university had a web services unit in the Office of Communication and Marketing. We scheduled a meeting with their Web Development Services (WDS) consultants and took hard copies of the prototype, our mission statement, and our list of target audiences with us.

The meeting with WDS was both productive and frustrating. Their primary work was with high-level strategic initiatives for the entire university system. They could provide basic consultative services to schools, but this was not their principle function. It became apparent that engaging them to help develop our portal would result in significant delays. We mulled over the idea of cobbling together various parts of the portal from several other university sources. This, too, seemed equally fraught with problems and potential delays. That left us with the all too common dilemma-build or buy? We needed to decide whether we would design and build the portal ourselves or seek an external partner to complete the project. We asked the WDS staff to help craft a concise Memorandum of Understanding (MOU) that would focus our choices 4 . This became the key working document. The MOU included a vision statement, ranked target audiences, recommended solutions, identified quantitative and qualitative metrics, and provided an estimated timetable and costs.

The MOU outlined four possible solutions in increasing order of complexity and cost. We could:

1. Redesign the current static HTML site with similar functional limitations to the ones we had.

2. Build a website with some dynamic sections (news, calendar, etc.) and include databases and several administrativetool features.

3. Undertake a completely dynamic website using templates and a database repository. Robust administrative tools for content management of documents, images, audio, and video files with distributed publishing and workflow management capabilities could also be included. This would make it possible to have many different people working on the website continuously without bottlenecks and yet have the ability to oversee and control what was being posted.

4. Choosea robust solution with additional e-commerce, e-learning, and "push and pull" features. In this context, push and pull referred to complete integration with the Oncourse course management system and other information systems planned by the University.

Given the available resources and personnel capabilities, the first two solutions could have been built in-house. The third and fourth would require external help. The fourth solution was the most complex and would involve coordination with major university-wide initiatives. We elected to pursue the third option and retain a consultant. 
WPD recommended three firms that they had worked with in the past. We started by reviewing the firms' websites and tested them for disability access with the "Bobby" program (Watchfire, no date). "Bobby" allows you to analyze how well a website conforms to the World Wide Web Consortium (W3C, 2002) standards for disability access and the Federal Section 508 requirements. These are industry standards for website disability access (Wright, 2002). Only one of the three firms, Excel Communications, Inc., passed these crucial tests. Next, we asked for references from Excel's customers and followed up on them. The recommendations were positive: Excel Communications had successful experience working with higher education institutions and was quickly responsive to their customers. They understood some of our more Byzantine organizational characteristics. In addition, they had experience with portals and content management systems (CMS). Their past projects involved design, development, and implementation of "off the shelf" CMS products. Most importantly, they had developed their own CMS solution in response to client needs. The product was called Plexcor and was built using open source Microsoft protocols-a common industry standard-that we felt would havestaying power. We began a relationship with Excel Communications. This produced a contractual agreement including planning and consulting services, creative services (design, development, and implementation), and the Plexcor application. This was the most critical juncture- we had made a formal commitment to the portal project and found the help we needed to pursue it.

\section{PLANNING PHASE}

We began the session by brainstorming with the Excel team to develop a common vision of what success would look like if we looked back five years from now. We used our mission statement as the basis for this discussion. Next, we went back over the list of target audiences and reviewed the groupings. The Excel team encouraged us to rank the audiences in order of importance. We then listed strengths, weaknesses, opportunities, and possible threats that could result from the new web presence. Once everyone was on the same page, we developed strategies that would support our vision. We remained mindful that a portal was a means to communicate and not a strategy in and of itself. During the discussion we considered a broad range of topics. Not surprisingly, one of our main strategies involved developing our portal as our primary communications, marketing, and development tool.

At the same time, we compiled a list of possible sub-strategies and activities that we could initiate: We wanted to showcase research activities, develop collaborative teaching resources, convey what you can do with a social work degree, promote prospectivestudents, cultivate alumni, nurture current students, and develop new relationships with organizations through hosting services.

We discussed the features and functions we wanted included in the portal from the outset. It was time to take this knowledge and make it explicit. In collaboration with the Excel consultants, we came up with the following features and functions:

- The people who would maintain the portal and websites would not need technical skills such as writing, converting files to $\mathrm{HTML}$, or placing them on the server. 
- Distributed publication would happen by as many people as needed rather than merely relying on one person or office.

- A workflow management process would be in place to control content by having a review-approval feature - so that problematic files could be re-edited before being made publicly available.

- Security, including the ability to control different degrees of access to editing and the uploading of documents and the ability to archive files and web pages taken out of circulation.

- Disability access at minimum compliance with W3C and Section 508 standards.

- The hosting of collateral organizations such as social work practice associations that need a web presence.

- The ability to add e-learning, especially for continuing and distance education, and e-commerce features if the school decided to pursue these in the future.

The final task of the planning phase involved the consultants developing a project review website. This website became our central hub as the project evolved. It was a convenient mechanism for storing documents, reviewing proposed designs, and archiving project information.

\section{DESIGN PHASE}

Once this job was done, we disbanded the task force and moved oversight of the project to the school's standing Technology Committee. The committee's first order of business was to agree on the methodology for moving the project forward with the Excel consultants. The User Centered Design approach (Norman \& Drapers, 1986), a dialog process for developing successful interaction between people and computers, was in widespread use at our university. Excel was experienced with this methodology, and the consultants had developed a project management matrix that could easily manage the project as it progressed from design to construction.

Our consultants recommended an "Integrated Marketing Communication" (IMC) approach (Schultz, Stanley, Tannenbaum \& Lauterborn, 1993) noting that the university's marketing group had been employing it with success for several years. IMC results in a seamless uniformity between media: websites echo printed materials, televised messages, and all other media used for public communication. Taking this approach required us to consider development of the overall creative concept for the portal-the "look and feel" and primary messages-as a cohesive whole (Percy, 1997). This would result in consistent designs and messages in all of the school's media including website, brochures and other promotional and scholarly materials. The concept would begin with our portal.

To develop our key message, we listed the school's attributes, which were unique and of value. In marketing terms, this is referred to as the "unique value proposition." We had strong brand recognition and an excellent reputation. As a result, we developed this key message:

Indiana University School of Social Work...Shaping Leaders Since 1911 


\section{Visual Design}

We initially began working with the consultants to develop the visual look for the website. This caused a fundamental change in our public relations documents. Many of the school's brochures for various programs, reports, and other public documents had evolved at different times over the years. This resulted in a confusing patchwork of many styles, colors, and layouts. The need for a uniform coherence was obvious. We needed to embrace the integrated marketing approach. As a result, apart from website development, Excel and the school developed creative concepts that included a common color palette that would be used both on the website and in paper publications. This crystallized the "look" for the portal and satellites.

The portal now had a uniform design that would be mimicked by all five campus programs. The colors would be unique for each campus but would still be from the same palette. Visitors would know that they were still within the school but on different campuses. With a little practice, a regular visitor such as a student would be able to immediately recognize where he or she was in the portal.

In the same manner, close attention was given to having some consistency with our host university's website through the use of visual cues. We portrayed the relationship subtly by re-using the same message, font, stylistic treatments, and logo as our university does in its key marketing strategy.

Excel then provided us with three different creative treatments. We tested how well the concepts resonated with users in all six target audiences during the prototype testing that took place when the information design was complete.

\section{Information Design}

With the initial planning and most of the design phase now complete, we were ready to begin designing the information architecture and navigational structure details for the portal and one of the campus websites. We elected to tackle the design and implementation of the portal, now called Indiana University School of Social Work and would develop the main campus website first. Subsequent development would follow for the other four campus sites. We deliberately decided on this approach because we felt that changing the entire five-campus system all at once would overwhelm us.

The first task was to design how the specified contents for the various audiences, programs, and campuses could fit together into a reasonably navigable whole. This proved to be daunting given the number of audiences and varied content specifications. The process evolved into a dialog: our consultants would give us a version of a sitemap. We would review it, give them feedback, and ask for an updated version that reflected our changes. When we got to the fifth version, we were ready for user testing. We needed feedback from users in all six target audiences before proceeding further.

\section{Prototype Usability Testing}

Usability is defined by The International Standards Organization (ISO) as the extent to which a product can be used by specified users to effectively achieve specific goals efficiently in a specified context of use (ISO, 1998). We started to gener- 
ate authentic tasks using the frequently asked questions collected during the planning phase. For example, the directors from the Ph.D., MSW, and BSW programs reviewed the questions and proposed tasks for their program area.

A paper mock-up was developed from text documents that represented potential web pages (Snyder, 2001). The pages were assembled into a loose-leaf binder. Each page had a numbered tab and the numbers represented links to other pages. This made it possible to simulate movement from one page to the next without actually developing the website.

We selected 10 representative users from the six target audiences. We wanted typical users, not people who were extremely enthusiastic, knowledgeable, or hostile to using technology, and so they were screened for a moderate level of computer experience and familiarity with the School of Social Work. The test sample was weighted toward females, which represents the school's population. Testing was conducted at the school, one test subject at a time. One of us would read an introductory script, then the test subject would try to accomplish 22 tasks and was asked questions pertaining to the design. The tasks simulated actual activities such as finding specific information about fieldwork in the BSW program. In accordance with UCD methods, iterative changes in the pages were made as testing progressed.

\section{Findings}

Observations and data from the paper tests were consolidated into a report. The findings and recommendations were grouped according to templatestyles (portal, campuses, and programs). The report listed 21 "Findings" and suggested 13 "Recommendations" for consideration. This produced a final sitemap when the recommendations from the usability testing were resolved and adopted.

Taken together, the sitemap planning process and usability testing produced a workable plan. The Excel technical staff developed an electronic prototype within three weeks. The Technology Committee reviewed it and additional modifications were made based on minor stylistic and content changes. We now had a clear plan for constructing the portal and its satellites.

\section{DEVELOPMENT AND IMPLEMENTATION PHASES}

\section{Hosting and Security}

We had to decide whether to host the portal on our own server or enter into a fee for-service agreement with an internal university service. The school had its own server at that time, but we had encountered security problems with it and maintaining a vigilant presence was getting to be a drain on our school's one technical support person. While no system is completely immune from attacks such as people attempting to store movie files, alter files as pranks, or worse, our university could provide a far more robust environment. As a result, we decided to go with the university's hosting services. This decision gave us the advantage of not having to worry about security and also provided the opportunity to host a test-bed website for the prototype. We could populate the new portal and its associated websites while keeping the old website in service. This would allow us to finetune navigation and content before rolling out the new portal and help with training. 


\section{RoleAssignments}

Our consultants installed the prototype and we created a preliminary list of content managers, the people who would have responsibility for specific content areas within the portal. For example, someone from the MSW field office would need to develop and maintain content regarding practicum activities. "User groups" could be created with different levels of access to the portal and the IUPUI campus website. We initially created four groups, which included "owners," the people with complete access and decision control over all aspects of the website. A "security" group consisting of the owners and our technical support person was added to regulate access. A "managers" group was created for people with administrative responsibilities. Finally, an "editors" group was created. These would be the people who would actually enter web content and the managers would beable to approve that content. Assignments to specific groups were made by the school's "Administrative Team," the group charged with oversight of all of the school's production routines. Group assignment was based on the staff person's role and responsibilities. Pass-worded access was given to each individual depending on their assigned group.

\section{Training}

Our consultants then held two field-training sessions. The preliminary documentation for managing the website was not adequate from a "read it-do it" viewpoint. This was largely due to the fact that the Plexcor program is menu based, not graphics based, making it sometimes difficult to understand where you are in the program. This made it important to have hands-on training and experience in addition to the documentation. These sessions focused on the direct skills needed to gain access to the system, how to upload different types of files, set navigation, and edit web page content. In addition, Excel provided a lengthy technical instruction session with one of us, who, as a site owner, would also have occasional instructional responsibilities.

\section{Workfiow}

The initial workflow procedures, such as assigning who was responsible for providing and editing content, began to evolve as more people contributed to the portal's database. We discovered that overall management and navigation decisions needed to be made by the site owners because of features in the Plexcor system. The navigation features were too challenging for some staff. This resulted in a prototype website that was both centrally managed and yet access-distributed on a controlled basis: exactly what we wanted!

\section{Launch}

At this point we had to decide when to take the portal out of the test-bed and present the websites to the public. We still had incomplete data files and occasional gaps where content should have been available but was not. Yet, to delay longer would simply continue dependence on our older, inadequate website. Expectations had been raised and we needed to deliver on them, even if the product was incomplete. We decided to roll out the portal and the IUPUI website at the beginning of October, 2002, with the expectation that enough of the database 
would be complete by the end of the semester that people would start becoming dependent on it for routine information.

\section{EVALUATION AND ASSESSMENT}

What worked and what did not?While a summative evaluation of the portal's effectiveness is premature, several issues concerning how well it has worked and nuances around the development process merit discussion. These are based on observation, experience, and discussion. One key issue is monitoring organizational change and management issues.

\section{Change Management}

Innovation often takes place outside of the organization's official hierarchy. This project was no exception. Many people with varying statuses had participated throughout the formative stages of the project. This resulted in a wide degree of buy-in and certainly fostered designs that addressed many needs. Yet, onceup and running, some administrative control over content became necessary. As a result, oversight and policy finality was transferred from the school's Technology Committee to the school's Administrative Team. This group consists of our dean, the three directors for the different degree programs, the director of research, and the director of development. With this policy established, the evolution of routines and who would be responsible for them began to evolve. Since "no single quality of management practice is more highly correlated with success than [participation]" (Deetz, Tracy \& Simpson, 2000), it was fortunate that these individuals had been keenly involved in the portal development and were very supportive of it from the start.

\section{Marketing and Promotion}

Little energy was devoted to advertising and promotional planning for the portal at rollout because the databases were incomplete. What would be accomplished by attracting visitors to an incomplete website? We began to turn our attention to promoting the portal and its content once peoplestarted to add content. Whilethe portal project began independently, the collateral efforts to create a uniform or "branded" look and feel for all external communications collateral for the school were in development as well. As a result, we missed an initial opportunity to crosspromote between the various marketing and communication channels.

\section{Assessment Metrics}

Assessment metrics are included in the Plexcor module to help determine frequencies and patterns of use. Unlike the rather useless logfiles from theolder website, this feature provides quantitative measures such as the number of hits per web page per unit of time, page hit frequencies, and hierarchic relationships between web pages. The measures show more visitors are regularly hitting the IUPUI website than the portal page. This suggests that visitors look for campusspecific information more than general information about the school. The visitation patterns suggest targeted search. For example, information-laden web pages about the MSW program have a high visit frequency followed by web pages with more specific information, then by web pages on application information. This suggests a pattern of inquiry, exploration, and commitment on the part of poten- 
tial students. The research section of the website enjoys high use as well. These aggregate measures have been gratifying because they indicate that, at least for the prospective student and research audiences, the portal is beginning to support them.

\section{Lessons Learned}

The process we followed-initially envisioning what we needed, then consolidating it into a mission statement that was endorsed by the faculty-was probably the most critical part of the planning process. The vision whetted appetites for what could be. The mission was the foundation for our goals.

The initial efforts at defining the portal's audiences, then conducting usability testing, were most worthwhile. These efforts helped transition the mission statement from general intentions to specific and concreteoperational objectives. They also clearly informed everyone about just how complex and how long the endeavor would take. This led to reasonable expectations. The fact that we put a great deal of energy and effort into this-prior to writing a single line of code-clearly paid off as very few user complaints were voiced after rollout.

Earlier attention to administrative structures and policies for the website would have been helpful. We had occasional conflicts over just what content needed to be placed within the portal and where it should be located. These conflicts tended to be mechanical rather than philosophical, though, and did not impede progress. Additional issues such as who would be responsible for them while initially mapped out evolved into different personnel needs and patterns. In a sense, the loose coupling of various constituencies during the design and implementation process may have been helpful, but rationalizing the results earlier in the process might have resulted in a more complete product at rollout.

Our decision to use professional designers and developers was invaluable. The efficiencies gained were worth the investment. Had the school tried to develop the portal with internal and intramural resources, the results would certainly have been an inadequate portal way past deadline. The visual consistency among campuses might not have emerged. The system for managing information on the website would have been far more arcane.

Adequate financing was also very pivotal in our success. Our dean was extremely supportive. Having a competitively bid price for the entiresystem rather than contracting with technical personnel on an hourly basis was efficient and resulted in more collaborative involvement with the consulting firm. Contracting with numerous independent consultants instead for bits and pieces of the system would have courted disaster. Coordination and compatibility would probably have been a major problem had we chosen this alternative, plus the time drain on staff would have been prohibitive. The planning of revenue streams to eventually amortize investment costs and sustain the system in the future, discussed from the outset but still on our horizon, was very helpful in generating support from key administrative personnel.

Our security and currency concerns have been marginal. While we initially set up a hierarchy whereeditors' work would be reviewed and approved by the manager's 
group, this was not necessary. The portal system fosters mutual oversight among contributors. This has resulted in quick error correction and the elimination of obsolete information.

Finally, the relationship between our vendor, Excel, and the school was instrumental in the portal's current and growing success. Selecting a firm that could guide development and extend support beyond rollout through maintenance agreements was crucial. The spin-offs, such as gaining a uniform marketing strategy and "look" where previously there had been far too much variation, were invaluable.

\section{PLANNING FOR THE FUTURE}

Why go to the trouble of developing a complete portal system when individual static websites have worked in the past? Why create an initiative when university personnel are often willing to build "brochure" websites for programs? The portal approach holds several distinct advantages.

First, people are gravitating toward the web as their first source for information. This means that a recruitment-directed website will not serve other audiences such as research colleagues, alumni, or current students very well. A morecomplex environment, built from the ground up to meet the needs of multiple audiences, is far more engaging. This advances the school's mission. In addition, a dynamic portal system can be adapted to computer applications that evolve within the university. New campus-wide innovations such as additional online services and information resources can be easily incorporated into the portal. This allows the school to seamlessly integrate itself into the university's computing environment rather than just being an isolated source for information. The school, in return, is perceived as a player instead of just an observer.

Next, a distributed system encourages "buy in" because many people are participating in its ongoing maintenance and growth. A sense of collective ownership generates enthusiasm. New ideas can be quickly implemented. A static website maintained by one or two individuals cannot do this. This encourages growth and innovation for the entire school. For example, rural social workers often have problems finding supervision for licensure. We are considering a web-based service that can mediate supervision online. A static website cannot do this. Online training for licensure continuance or other continuing education activities can also be supported by a dynamic system. A static website cannot do this. Our portal's ability to develop online surveys for research or marketing opens new horizons for interacting with many audiences as well. Data solicitation and collection is easy in a dynamic system. A static website cannot do this.

Schools also have the obligation to help support the practice community. Specialized groups of practitioners often want websites. Some organizations have volunteer-maintained websites but many of these are not well designed or maintained. Other organizations simply do not have the means to sustain a website on their own. The portal approach offers the ability to create a sophisticated web presence for these organizations. For example, we now host the Association of Baccalaureate Social Work Directors (BPD) web site: http://bpdonline.org. Select 
members from BPD have password access to this website and the only skill needed is to be able to upload text files. Behind the scenes, the template and management shell for the BPD website is simply another extension of our school's portal. Support initiatives for affiliated organizations thus become possible, furthering the mission of the profession. This type of hosting service works well without draining the school's resources.

Finally, the portal system fosters quality teaching. The classic problem of quickly orienting new faculty or supporting adjunct colleagues can beeased through making teaching resources readily available in secure parts of the portal. We are currently developing password accessible resources for faculty through our "Indiana University Resource Online Collection" (IUROCS) initiative. The website will contain syllabi, lists of media used in each class, testbanks, and voluntarily provided teaching materials such as PowerPoint files and lecture outlines. This will help new instructors, plus it has the added benefit of showing faculty what teaching materials other colleagues are using. This should eliminate the problem of students rolling their eyes in class because they have "seen this movie before." In terms of the Council on Social Work Education's Educational Policies and Accreditation Standards (EPAS), the initiative will directly support non-repetitive learning plus horizontal and vertical integration (Council on Social Work Education, 2003). Classroom management programs cannot do this well.

All of these benefits provide the flexibility to adapt to an ever-changing and growing electronic world. Through creating portals, we can define and expand our roles ourselves rather than being guided by others who understand little of the social work education mission.

\section{Endnotes}

${ }^{2}$ While generating a basic HTML page is relatively easy-most word processing programs can save a text document for Web display-generating one that can be accurately rendered by many different browsers that are running on many different platforms is considered more difficult. A good metaphor is photography: Anyone can take a snapshot, but crafting a professional photograph takes far more considerable skill.

'The term "Portal" is not well defined. A "shopping mall" metaphor is often invoked. Common definitions include one-point entry via a main homepage and easy use through extensive navigation aids including sophisticated search engines, "breadcrumbs" that tell the user where they are in the website and how they got there, and other features that facilitate easy access to vast amounts of information. Additional features may include chat abilities, newsletters, online shopping, and many other services. A good overview is available at About.com: http://compnetworking.about.com/library/ weekly/aa011900a.htm.

${ }^{3}$ At present, the main portal: http://socialwork.iu.edu has been developed along with one campus, http://socialwork.iupui.edu. Two other campuses are under construction and the remaining two are scheduled for development in 2004-2005.

${ }^{4}$ The complete Memorandum of Understanding is available at: $\underline{h t t p}: / /$ socialwork.iu.edu/site/indexer/ $\underline{121 / \text { content.htm }}$

\section{References}

Carlson, L. (2003). Web site evolution; Retrieved online July 23, 2003 from: http:// www.d.umn.edu/ -lcarlson/cms/evolution.html

Council on Social Work Education. (2003). Handbook of accreditation standards and procedures, (5 $5^{\text {th }} \mathrm{ed}$.). Alexandria, VA: Author. 
Curl, A., Bowers, R., \& Bowers, D. (2003). Future of website design: Accessi bility as an issue of social justice. Paper presented at the annual meeting of the Council on Social Work Education, Atlanta, GA.

Deetz, S., Tracy, S., \& Simpson, J. (2000). Leading organizations through transition. Thousand Oaks, CA.: Sage Publications, Inc.

International Standards Organization, ISO 9241-11: Ergonomic requirements for office work with visual display terminals (VDTs); Part 11-Guidance on usability (International Standards Organization, 1998).

Nielsen, J. (1999). Designing web usability: The practice of simplicity, Indianapolis, IN: New Riders Publishing.

Norman, D., \& Drapers, S. (Eds.). (1986). User centered system design. Hillsdale, NJ: Lawrence Erlbaum Associates.

Percy, L. (1997). Strategies for implementing integrated marketing communication. Lincolnwood, II: NTC Publishing Group.

Powell, W., \& Gill, C. (2003). Web content management systems in higher education, EDUCAUSE Quarterly, 26(2), 43-50.

Schultz, D., Stanley, I., Tannenbaum, R., \& Lauterborn, R.F. (1993). Integrated marketing communication. Lincolnwood, II: NTC Publishing Group.

Snyder, C. (2001). Paper prototyping. Retrieved online on June 12, 2001 from: http://www106.ibm.com/developerworks/library/us-paper/?dwzone=usability

Spool, J. (2001). User engineering institute. Retrieved online on June 12, 2001 from: http://www.uie.com

Vernon, R., \& Lynch, D. (2000). Social work and the web. Pacific Grove, CA: Brooks-Cole.

Vernon, R., \& Lynch, D. (2003). Consumer access to agency websites: Our best foot forward? Journal of Technology in Human Services, 21(14), 37-51.

Watchfire. (no date). Bobby onlinefreeporta. Retrieved online October 3, 2003 from: http:// watchfire.com

World Wide Web Consortium (W3C): Web accessibility initiative. Retrieved online December 27, 2002 from: http:// www.w3.org/WAl/

Wright, J. (2002) Website development does not have to mean denying accessibility. Journal of Technology in Human Services, 19(4), 111-114.

\section{Author's Note:}

Address correspondenceto: Robert Vernon, Ph.D., Indiana University School of Social Work, 902 West New York Street, Indianapolis, IN 46202, USA. E-mail: rvernon@iupui.edu 